\title{
PLANTAÇÕES FLORESTAIS E A PROTEÇÃO DE FLORESTAS NATIVAS EM UNIDADES DE MANEJO CERTIFICADAS NO BRASIL ${ }^{1}$
}

\author{
Ricardo Ribeiro Alves², Laércio Antônio Gonçalves Jacovine ${ }^{3}$ Márcio Lopes da Silva ${ }^{3}$
}

\begin{abstract}
RESUMO - A certificação florestal tem-se expandido pelos vários estados do Brasil, tanto na modalidade de plantações florestais quanto nas florestas nativas. Este trabalho teve por objetivo principal analisar a contribuição que a certificação de plantações florestais tem na proteção de florestas nativas nos estados brasileiros pelos sistemas FSC e CERFLOR. Foram consultados os resumos públicos das unidades de manejo florestal certificadas nos estados brasileiros, tanto os referentes à certificação de plantações florestais quanto os referentes a florestas nativas. Buscou-se a informação referente à área total certificada da unidade de manejo florestal e, no caso de plantações florestais, a área efetiva de plantações, a área de proteção florestal e a área destinada a outros usos. A área total de floresta nativa certificada é de 2,78 milhões de hectares, enquanto a de plantações florestais é de pouco mais de quatro milhões de hectares. As áreas protegidas no Estado da Bahia são as maiores pelo CERFLOR (46,35\%) e a segunda maior pelo FSC (40,67\%), ao passo que as menores áreas destinadas a esse fim estão no Estado de São Paulo, com 23,33\% pelo CERFLOR e 21,02\% pelo FSC. Estados da Região Amazônica destinam percentual maior de área de proteção florestal. Conclui-se que as empresas que detêm a certificação de plantações florestais exercem importante função na proteção florestal, pois, em muitos casos, essas empresas cumprem um percentual muito maior do que o exigido pela lei. Escolher um ou outro sistema de certificação não influencia no maior grau de exigência com relação à proteção de espécies nativas.
\end{abstract}

Palavras-chave: Certificação florestal, Proteção florestal e Sistemas de certificação.

\section{FOREST PLANTATIONS AND THE PROTECTION OF NATIVE FORESTS IN CERTIFIED MANAGEMENT UNITS IN BRAZIL}

\begin{abstract}
Forest certification has expanded in several states in Brazil both in the form of forest plantations and native forests. The main objective of this study was to analyze the contribution that certification of forest plantations has in the protection of native forests in Brazilian states through the systems FSC and CERFLOR. It was consulted the public summaries of certified forest management units in the Brazilian states, both concerning the certification of forest plantations and native forests. It was searched information on the total certified area of forest management unit and for the forest plantations, the effective area of plantations, the area of forest protection and forest area assigned for other uses. The total area of certified native forest is 2.78 million hectares whereas the area of forest plantations is a little over four million hectares. Areas protected in the state of Bahia are the largest by CERFLOR (46.35\%) and the second largest by FSC (40.67\%), whereas the smallest areas assigned for this use are in the state of São Paulo, with 23.33\% by CERFLOR and 21.02\% by the FSC. States in the Amazon region assign a higher percentage of area for forest conservation. It is concluded that enterprises which have certification of forest plantations have an important role in forest conservation because since in many cases, those enterprises comply with a percentage much higher than that required by law. To choose one or other certification system does not influence the degree of demand with respect to the conservation of native species.
\end{abstract}

Keywords:Forest certification, Forest conservation and Certification systems.

\footnotetext{
${ }^{1}$ Recebido em 05.04.2009 e aceito para publicação em 20.04.2011.

${ }^{2}$ Universidade Federal do Pampa, Campus São Gabriel (RS), UNIPAMPA, Brasil. E-mail: <ricardoalves@unipampa.edu.br>.

${ }^{3}$ Departamento de Engenharia Florestal, Universidade Federal de Viçosa, UFV, Brasil. E-mail: < jacovine@ufv.br> e < marlosil@ufv.br> .
} 


\section{INTRODUÇÃO}

O interesse da sociedade pelas questões referentes ao meio ambiente cresceu nas últimas décadas e o Brasil, após a abertura econômica no final da década de 1980, passou a sofrer mais de perto essas influências.

Ao final da década de 1980, em alguns países surgiram iniciativas de boicotar o consumo de produtos tropicais como uma forma de desestimular a destruição das florestas. No entanto, esse boicote poderia agravar o desmatamento nos trópicos, uma vez que, com a queda do valor da madeira e das áreas florestais, poderia ser favorecido outros usos mais predatórios da terra, como pastagens e atividades agrícolas. $\mathrm{O}$ fator mais importante para explicar o fracasso do boicote na redução do desmatamento foi o fato de que grande parte da madeira produzida nos trópicos era consumida dentro dos próprios países. Dados de 1999 indicam que mais de 85\% da madeira produzida na Amazônia era consumida dentro do Brasil, portanto a ação de boicote e a redução do consumo externo atingiriam apenas pequena parcela da produção de madeira. Dessa forma, em vez de prejudicar toda uma classe de produtos, foram propostos o reconhecimento e consumo de bens florestais produzidos sob prática do “Bom Manejo” e que seriam atestados por uma certificação, que passou a ser conhecida como certificação florestal (VIEHBEC, 2001; NARDELLI, 2001; AZEVEDO; FAILLACE, 2005).

De acordo com Baharuddin e Simula (1994), a certificação florestal é um processo que resulta em um documento escrito, emitido por um terceiro independente, atestando que o manejo florestal de uma unidade está em conformidade com padrões predeterminados. Para Pereira e Vlosky (2006), a certificação florestal também permite garantir aos consumidores que o produto oriundo da floresta atende a requisitos como responsabilidade ambiental, benefícios sociais e viabilidade econômica, sustentando, assim, o manejo florestal.

O primeiro sistema de certificação florestal (selo verde), o Forest Stewardship Council -FSC (Conselho de Manejo Florestal) foi criado em 1993. Uma ONG criada com o intuito de harmonizar o processo de certificação florestal, constituindo-se numa organização internacional independente, formada por representantes do movimento ambiental, pesquisadores, produtores de madeira, comerciantes de produtos florestais e populações tradicionais e, atualmente, com sede na Alemanha (NARDELLI; GRIFFITH, 2003).
Atua também como sistema de certificação no Brasil, o CERFLOR. Este representa uma iniciativa brasileira e não possui relação com o FSC, sendo, portanto, independente dele. Em 2005, o CERFLOR obteve o reconhecimento mútuo do Programme for the Endorsement of Forest Certification Schemes (PEFC Council), sistema europeu de certificação florestal. O PEFC foi fundado em 1999, e é uma organização independente, não governamental e sem fins lucrativos, que promove a sustentabilidade do manejo florestal, por meio de terceiros. Esse sistema é baseado em critérios definidos nas resoluções das Conferências de Helsinki e de Lisboa sobre Proteção Florestal na Europa (NARDELLI, 2005; PEFC, 2009).

Existem duas modalidades de certificação implementadas pelos órgãos credenciados pelo FSC: a) Certificação do Manejo Florestal, quando são certificadas as operações de manejo florestal que atendem aos Princípios e Critérios do FSC; b) Certificação de Cadeia de Custódia (CoC), quando são certificados os produtos florestais através do uso do "selo verde" nesses produtos, com a inspeção de toda a cadeia produtiva, tendo-se a garantia que toda a matéria-prima utilizada teve sua origem em florestas certificadas. Esse fato é importante porque, muitas vezes, o produto florestal, originado numa unidade de manejo certificada, é transportado e processado por diferentes organizações, até chegar ao consumidor final (IMAFLORA, 2002; NARDELLI; TOMÉ, 2002). A certificação de cadeia de custódia está presente em diversas indústrias do setor florestal, como a moveleira, por exemplo (JACOVINE et al., 2006; ALVES et al., 2009a, b).

Para a certificação de plantações florestais, deve ser observada a exigência da lei quanto à área a ser protegida com espécies nativas. O Código Florestal Brasileiro, criado em 1965, trouxe um novo disciplinamento para as florestas e as demais formas de vegetação existentes no território nacional e que estes recursos foram reconhecidos como de utilidade para as terras que revestem, estabelecendo que são bens de interesse comum a todos os habitantes do país. Além disso, os direitos de propriedade passaram a ser exercidos com as limitações da legislação em geral e especialmente daquelas criadas pelo novo código (CORRÊA, 2006). No entanto, Jacovine et al. (2008) destacaram que há um desrespeito generalizado à legislação florestal e, 
devido à importância ambiental das áreas florestais, passa a ser necessário conhecer os possíveis obstáculos à sua efetivação.

Torna-se, dessa forma, importante avaliar a área que tem sido destinada à proteção florestal, no caso da certificação de plantações florestais. Assim, este trabalho teve por objetivo principal analisar a contribuição que a certificação de plantações florestais tem na proteção de florestas nativas nos estados brasileiros pelos sistemas FSC e CERFLOR. De forma específica, buscou-se:

- Analisar a área certificada nos estados brasileiros, tanto pelo FSC quanto pelo CERFLOR.

- Avaliar a área certificada referente a plantações florestais e florestas nativas nos estados.

- Analisar o percentual de proteção florestal destinado nas áreas certificadas FSC e CERFLOR de plantações florestais, nesses estados.

- Efetuar uma comparação entre a certificação de plantações florestais e a proteção de florestas nativas nos sistemas FSC e CERFLOR.

\section{MATERIAL E MÉTODOS}

Para a realização do trabalho foram consultados os resumos públicos das unidades de manejo florestal certificadas nos estados brasileiros, tanto os referentes à certificação de plantações florestais quanto de florestas nativas. Os resumos públicos foram obtidos dos dois sistemas de certificação atuantes no país, FSC e CERFLOR (que possui reconhecimento do sistema europeu PEFC) e nas certificadoras aos quais estão vinculados.

A utilização de documentos, como os resumos públicos, em pesquisas científicas foi destacado por Gil (2008). Segundo ele, o uso de fontes documentais é capaz de proporcionar ao pesquisador dados em quantidade e qualidade suficiente para evitar a perda de tempo e o constrangimento que caracterizam muitas das pesquisas em que os dados são obtidos diretamente das pessoas. Além disso, em muitos casos só se torna possível realizar determinado tipo de investigação por meio de documentos.

Nos resumos, buscou-se a informação referente à área total certificada da unidade de manejo florestal e, no caso de plantações florestais, a área efetiva de plantações, a área de proteção florestal e a área destinada a outros usos.
Primeiramente, os dados foram organizados por estados da federação e sistema de certificação. Posteriormente, foi feita uma divisão entre a área de florestas nativas e de plantações florestais. Finalmente, foi feita uma comparação entre os estados que possuíam certificação de plantações florestais pelos dois sistemas de certificação, de acordo com os dados de suas áreas certificadas.

\section{RESULTADOS E DISCUSSÃO}

\subsection{A certificação florestal nos estados brasileiros}

Em 1995 foi certificada a primeira unidade de manejo florestal no Brasil, pertencente à empresa Duratex, situada no Estado de São Paulo. Desde então, vários estados da federação possuem unidades de manejo certificadas, tanto pelo FSC quanto pelo CERFLOR.

No Brasil, a área total certificada pelo FSC é quatro vezes e meia maior que a do CERFLOR, que, entretanto, tem crescido nos últimos anos, após o reconhecimento do sistema europeu PEFC.

Do total de 26 estados brasileiros, 50\% deles já possuem áreas certificadas. Em alguns estados, mais de $2 \%$ de suas áreas são cobertas por florestas certificadas, como é o caso de Santa Catarina (3,21\%), Paraná (2,53\%), Pará (2,21\%) pelo sistema FSC e do Espírito Santo (3,73\%) pelo CERFLOR. Além do FSC, Santa Catarina e Paraná também possuem áreas certificadas pelo CERFLOR, o que eleva a área certificada nesses estados (Tabela 1 ).

Alguns estados, principalmente da Região Amazônica, ainda possuem áreas muito pequenas quando comparadas com sua área total, como nos casos do Amazonas (0,08\%) e Mato Grosso (0,05\%), além de estados que nem possuem áreas certificadas como Roraima e estados da Região Nordeste.

\subsection{Comparação entre as áreas certificadas de plantações florestais e florestas nativas pelos sistemas FSC e CERFLOR no Brasil}

As áreas certificadas pelo FSC no Brasil são bem divididas quanto ao tipo de floresta, pois 52,10\% do total são de plantações florestais e 47,90\% de florestas nativas, ao passo que, pelo CERFLOR, há predominância da certificação de plantações florestais $(94,10 \%)$ em relação às florestas nativas (5,90\%), conforme apresentado nos Tabelas 2 e 3.

Revista Árvore, Viçosa-MG, v.35, n.4, p.859-866, 2011 
Tabela 1 - Área certificada dos sistemas FSC e CERFLOR nos estados brasileiros - Dezembro de 2008.

Table 1 - Areas certified by FSC and CERFLOR systems in Brazilian states - December 2008.

\begin{tabular}{|c|c|c|c|c|c|c|c|}
\hline & \multirow[t]{2}{*}{ Estado } & \multicolumn{2}{|c|}{ Área do Estado } & \multicolumn{2}{|c|}{ FSC } & \multicolumn{2}{|c|}{ CERFLOR } \\
\hline & & $\mathrm{km}^{2}$ & $\begin{array}{c}\text { Hectares } \\
\left.1 \mathrm{~km}^{2}=100 \mathrm{ha}\right)\end{array}$ & $\begin{array}{c}\text { Área } \\
\text { certificada(ha) }\end{array}$ & $\begin{array}{c}\text { \% Área do } \\
\text { Estado }\end{array}$ & $\begin{array}{c}\text { Área } \\
\text { certificada(ha) }\end{array}$ & $\begin{array}{c}\text { \% Área } \\
\text { do Estado }\end{array}$ \\
\hline $1^{\circ}$ & Amazonas & 1.570 .745 & 157.074 .500 & 125.129 & 0,08 & 0 & 0,00 \\
\hline $2^{\circ}$ & Pará & 1.247 .689 & 124.768 .900 & 2.757 .868 & 2,21 & 0 & 0,00 \\
\hline $3^{\circ}$ & Mato Grosso & 903.357 & 90.335 .700 & 42.125 & 0,05 & 0 & 0,00 \\
\hline $4^{\circ}$ & Minas Gerais & 586.528 & 58.652 .800 & 624.314 & 1,06 & 435.571 & 0,745 \\
\hline $5^{\circ}$ & Bahia & 564.692 & 56.469 .200 & 425.622 & 0,75 & 211.689 & 0,37 \\
\hline $6^{\circ}$ & Rio Grande do Sul & 281.748 & 28.174 .800 & 69.068 & 0,25 & 142.704 & 0,51 \\
\hline $7^{\circ}$ & São Paulo & 248.209 & 24.820 .900 & 353.324 & 1,42 & 99.828 & 0,40 \\
\hline $8^{\circ}$ & Rondônia & 237.576 & 23.757 .600 & 112.416 & 0,47 & 73.059 & 0,31 \\
\hline $9^{\circ}$ & Paraná & 199.314 & 19.931 .400 & 503.389 & 2,53 & 49.843 & 0,25 \\
\hline $10^{\circ}$ & Acre & 152.581 & 15.258 .100 & 97.410 & 0,64 & 0 & 0,00 \\
\hline $11^{\circ}$ & Amapá & 142.814 & 14.281 .400 & 247.180 & 1,73 & 0 & 0,00 \\
\hline $12^{\circ}$ & Santa Catarina & 95.346 & 9.534 .600 & 305.673 & 3,21 & 53.422 & 0,56 \\
\hline $13^{\circ}$ & Espírito Santo & 46.077 & 4.607 .700 & 0 & 0,00 & 171.823 & 3,73 \\
\hline & Área Certifica & Brasil & & 5.663 .518 & & 1.237 .939 & \\
\hline
\end{tabular}

Obs.: os demais estados da federação não possuem florestas certificadas nem pelo FSC nem pelo CERFLOR.

Fonte: Adaptado de FSC, 2009; PEFC, 2009; IBGE, 2009; SMARTWOOD, 2009; SGS, 2009; SCS, 2009; GFA, 2009; CONTROL UNION, 2009; IMO, 2009; CERFLOR, 2009; BRTÜV, 2009; TECPAR, 2009; BVQI, 2009.

Tabela 2 - Comparação das áreas certificadas totais, de plantações florestais e florestas nativas do sistema FSC, nos estados brasileiros - Dezembro de 2008.

Table 2 - Comparison of total certified areas, forest plantations and native forests of FSC system in Brazilian states - December 2008.

\begin{tabular}{|c|c|c|c|c|c|c|}
\hline & \multirow[t]{2}{*}{ Estado } & \multirow{2}{*}{$\begin{array}{l}\text { Área certificada } \\
\text { total pelo FSC (ha) }\end{array}$} & \multicolumn{2}{|c|}{ Plantações florestais } & \multicolumn{2}{|c|}{ Florestas nativas } \\
\hline & & & Área (ha) & $\%$ & Área (ha) & $\%$ \\
\hline $1^{o}$ & Pará & 2.757 .868 & 395.215 & 14,33 & 2.362 .653 & 85,67 \\
\hline $2^{\circ}$ & Minas Gerais & 624.314 & 624.245 & 99,99 & 69 & 0,01 \\
\hline $3^{\circ}$ & Paraná & 503.389 & 503.389 & 100,00 & 0 & 0,00 \\
\hline $4^{\circ}$ & Bahia & 425.622 & 425.622 & 100,00 & 0 & 0,00 \\
\hline $5^{\circ}$ & São Paulo & 353.324 & 353.324 & 100,00 & 0 & 0,00 \\
\hline $6^{\circ}$ & Santa Catarina & 305.673 & 305.673 & 100,00 & 0 & 0,00 \\
\hline $7^{\circ}$ & Amapá & 247.180 & 232.130 & 93,91 & 15.050 & 6,09 \\
\hline $8^{\circ}$ & Amazonas & 125.129 & 0 & 0,00 & 125.129 & 100,00 \\
\hline $9^{\circ}$ & Rondônia & 112.416 & 0 & 0,00 & 112.416 & 100,00 \\
\hline $10^{\circ}$ & Acre & 97.410 & 0 & 0,00 & 97.410 & 100,00 \\
\hline $11^{\circ}$ & Rio Grande do Sul & 69.068 & 68.999 & 99,90 & 69 & 0,10 \\
\hline $12^{\circ}$ & Mato Grosso & 42.125 & 42.125 & 100,00 & 0 & 0,00 \\
\hline Total & & 5.663 .518 & 2.950 .722 & 52,10 & 2.712 .796 & 47,90 \\
\hline
\end{tabular}

Fonte: Adaptado de FSC, 2009; SMARTWOOD, 2009; SGS, 2009; SCS, 2009; GFA, 2009; CONTROL UNION, 2009 ; IMO, 2009 ; BVQI, 2009. Source: Adapted from FSC, 2009; SMARTWOOD, 2009; SGS, 2009; SCS, 2009; GFA, 2009; CONTROL UNION, 2009 ; IMO, 2009 ; BVQI, 2009.

Pelo FSC, os Estados do Pará, Amapá, Minas Gerais e Rio Grande do Sul possuem certificação tanto de plantações florestais quanto de florestas nativas, no entanto a certificação de nativas dos dois últimos estados é de somente 69 ha. Verifica-se que estados da RegiãoAmazônica são os que concentram as maiores áreas de florestas nativas, ficando as de plantações florestais nos outros estados. A mesma linha de raciocínio vale para o CERFLOR, em que o Estado de Rondônia é o único que possui florestas nativas certificadas pelo sistema.

Revista Árvore, Viçosa-MG, v.35, n.4., p.859-866, 2011 
Tabela 3 - Comparação das áreas certificadas totais, de plantações florestais e florestas nativas do sistema CERFLOR nos estados brasileiros - Dezembro de 2008.

Table 3 - Comparison of total certified areas, forest plantations and native forests of CERFLOR system in Brazilian states - December 2008.

\begin{tabular}{|c|c|c|c|c|c|c|}
\hline & \multirow[t]{2}{*}{ Estado } & \multirow{2}{*}{$\begin{array}{l}\text { Área certificada (ha) } \\
\text { total pelo CERFLOR }\end{array}$} & \multicolumn{2}{|c|}{ Plantações florestais } & \multicolumn{2}{|c|}{ Florestas nativas } \\
\hline & & & Área (ha) & $\%$ & Área (ha) & $\%$ \\
\hline $1^{\circ}$ & Minas Gerais & 435.571 & 435.571 & 100,00 & 0 & 0,00 \\
\hline $2^{\circ}$ & Bahia & 211.689 & 211.689 & 100,00 & 0 & 0,00 \\
\hline $3^{\circ}$ & Espírito Santo & 171.823 & 171.823 & 100,00 & 0 & 0,00 \\
\hline $4^{\circ}$ & Rio Grande do Sul & 142.704 & 142.704 & 100,00 & 0 & 0,00 \\
\hline $5^{\circ}$ & São Paulo & 99.828 & 99.828 & 100,00 & 0 & 0,00 \\
\hline $6^{\circ}$ & Rondônia & 73.059 & 0 & 0,00 & 73.059 & 100,00 \\
\hline $7^{\circ}$ & Santa Catarina & 53.422 & 53.422 & 100,00 & 0 & 0,00 \\
\hline \multirow[t]{2}{*}{$8^{\circ}$} & Paraná & 49.843 & 49.843 & 100,00 & 0 & 0,00 \\
\hline & Total & 1.237 .939 & 1.164 .880 & 94,10 & 73.059 & 5,90 \\
\hline
\end{tabular}

Fonte: Adaptado de PEFC, 2009; CERFLOR, 2009; SGS, 2009; BRTÜV; 2009; TECPAR, 2009 ; BVQI, 2009.

Source: Adaptaded from PEFC, 2009; CERFLOR, 2009; SGS, 2009; BRTÜV; 2009; TECPAR, 2009 ; BVQI, 2009.

\subsection{Contribuição das empresas com certificação de plantações na proteção de florestas nativas brasileiras, pelos sistemas FSC e CERFLOR}

As empresas, ao buscarem a certificação de seus plantações florestais, têm, como primeira regra para certificar, respeitar a legislação. Entre as leis a que se sujeitam, está a obrigação de destinar um percentual de áreas para a Reserva Legal (RL). O percentual de Reserva Legal varia entre as regiões do Brasil, indo de $20 \%$ nas Regiões Sudeste e Sul a $80 \%$ na
Região Norte. Nas Tabelas 4 e 5, mostram-se que o percentual que as empresas com plantações florestais destinam à proteção florestal é acima de $30 \%$ na maior parte dos casos, de acordo com a análise feita por estado.

Pelo sistema FSC, em média, 40\% das áreas certificadas são destinadas à proteção florestal, enquanto pelo CERFLOR esse percentual é de 34\%. Estados da Região Amazônica, como o Pará, e que estão sujeitos a uma legislação mais rigorosa, destinam percentual maior de área de proteção florestal.

Tabela 4 - Comparação das áreas efetivas de plantações florestais, de proteção florestal e de outros usos na área certificada total de plantações florestais do sistema FSC nos estados brasileiros - Dezembro de 2008.

Table 4 - Comparison of effective areas of forest plantations, forest protection and other uses in the area of total certified forest plantations of FSC system in Brazilian states - December 2008.

\begin{tabular}{|c|c|c|c|c|c|c|c|c|}
\hline & \multirow[t]{2}{*}{ Estado } & $\begin{array}{l}\text { Área certificada total } \\
\text { de plantações florestais }\end{array}$ & \multicolumn{2}{|c|}{$\begin{array}{c}\text { Plantações florestais } \\
\text { efetivos }\end{array}$} & \multicolumn{2}{|c|}{ Proteção florestal } & \multicolumn{2}{|c|}{ Outro uso } \\
\hline & & pelo FSC (ha) & Área (ha) & $\%$ & Área (ha) & $\%$ & Área (ha) & $\%$ \\
\hline $1^{\circ}$ & Minas Gerais & 624.245 & 358.132 & 59,94 & 203.617 & 34,10 & 62.496 & 10,46 \\
\hline $2^{\circ}$ & Paraná & 503.389 & 263.232 & 52,74 & 192.660 & 38,60 & 47.497 & 9,56 \\
\hline $3^{\circ}$ & Bahia & 425.622 & 212.360 & 49,89 & 173.104 & 40,67 & 40.158 & 9,44 \\
\hline $4^{\circ}$ & Pará & 395.215 & 123.147 & 31,16 & 272.068 & 68,84 & 0 & 0,00 \\
\hline $5^{\circ}$ & São Paulo & 353.324 & 251.714 & 66,26 & 79.862 & 21,02 & 21.747 & 5,73 \\
\hline $6^{\circ}$ & Santa Catarina & 305.673 & 154.062 & 49,70 & 129.610 & 41,81 & 22.001 & 7,10 \\
\hline $7^{\circ}$ & Amapá & 232.130 & 106.091 & 45,70 & 120.834 & 52,05 & 5.203 & 2,24 \\
\hline $8^{\circ}$ & Rio Grande do Sul & 68.999 & 42.417 & 61,48 & 19.326 & 28,01 & 7.254 & 10,51 \\
\hline & Total & 2.950 .722 & 1.532 .626 & 51,94 & 1.205 .927 & 40,87 & 212.169 & 7,19 \\
\hline
\end{tabular}

Fonte: Adaptado de FSC, 2009; SMARTWOOD, 2009; SGS, 2009; SCS, 2009; GFA, 2009; CONTROL UNION, 2009; IMO, 2009; BVQI, 2009. Source: Adapted from FSC, 2009; SMARTWOOD, 2009; SGS, 2009; SCS, 2009; GFA, 2009; CONTROL UNION, $2009 ;$ IMO, 2009 ; BVQI, 2009. 
Tabela 5 - Comparação das áreas efetivas de plantações florestais, de proteção florestal e de outros usos na área certificada total de plantações florestais do sistema CERFLOR nos estados brasileiros - Dezembro de 2008.

Table 5 - Comparison of effective areas of forest plantations, forest protection and other uses in the total certified area of forest plantations of CERFLOR in the Brazilian states - December, 2008.

\begin{tabular}{|c|c|c|c|c|c|c|c|c|}
\hline & \multirow[t]{2}{*}{ Estado } & \multirow{2}{*}{$\begin{array}{c}\text { Área certificada total } \\
\text { de plantações florestais } \\
\text { pelo CERFLOR (ha) }\end{array}$} & \multicolumn{2}{|c|}{$\begin{array}{c}\text { Plantações florestais } \\
\text { efetivos }\end{array}$} & \multicolumn{2}{|c|}{ Proteção florestal } & \multicolumn{2}{|c|}{ Outro uso } \\
\hline & & & Área (ha) & $\%$ & Área (ha) & $\%$ & Área (ha) & $\%$ \\
\hline $1^{o}$ & Minas Gerais & 435.571 & 227.984 & 52,34 & 138.146 & 31,72 & 69.440 & 15,94 \\
\hline $2^{\circ}$ & Bahia & 211.689 & 95.952 & 45,33 & 98.123 & 46,35 & 17.614 & 8,32 \\
\hline $3^{\circ}$ & Espírito Santo & 171.823 & 104.260 & 60.68 & 57.663 & 33,56 & 9.900 & 5,76 \\
\hline $4^{\circ}$ & Rio Grande do Sul & 142.704 & 83.888 & 58,78 & 47.861 & 33,54 & 10.955 & 7,68 \\
\hline $5^{\circ}$ & São Paulo & 99.828 & 71.380 & 71,50 & 23.294 & 23,33 & 5.154 & 5,16 \\
\hline $6^{\circ}$ & Santa Catarina & 53.422 & 30.725 & 57,51 & 19.103 & 35,76 & 3.594 & 6,73 \\
\hline \multirow[t]{2}{*}{$7^{\circ}$} & Paraná & 49.843 & 30.136 & 60,46 & 16.081 & 32,26 & 3.626 & 7,27 \\
\hline & Total & 1.164 .880 & 644.326 & 55,31 & 400.271 & 34,36 & 120.283 & 10,33 \\
\hline
\end{tabular}

Fonte: Adaptado de PEFC, 2009; CERFLOR, 2009; SGS, 2009; BRTÜV, 2009; TECPAR, 2009 ; BVQI, 2009.

Source: Adapted from PEFC, 2009; CERFLOR, 2009; SGS, 2009; BRTÜV, 2009; TECPAR, $2009 ;$ BVQI, 2009.

Analisando os seis estados brasileiros que possuem áreas de plantações florestais certificados pelos dois sistemas, FSC e CERFLOR, verificou-se como os percentuais destinados à proteção de florestas nativas são similares (Tabela 6).

As áreas protegidas no Estado da Bahia são as maiores pelo CERFLOR (46,35\%) e a segunda maior pelo FSC (40,67\%), ao passo que as menores áreas destinadas a esse fim estão no Estado de São Paulo, com 23,33\% pelo CERFLOR e 21,02\% pelo FSC. De qualquer forma, a obtenção de uma certificação de manejo florestal exige que as empresas cumpram o mínimo exigido pela lei quanto às áreas destinadas a RL e APP.

Há um equilíbrio entre o rigor dos sistemas FSC e CERFLOR na observância da proteção florestal. Em três estados, o FSC apresentou índices maiores que o CERFLOR: Minas Gerais, Paraná e Santa Catarina. Em contrapartida, o CERFLOR apresentou percentuais maiores em três estados, que também foram Bahia, Rio Grande do Sul e São Paulo. Assim, verificou-se que escolher um ou outro sistema de certificação não influencia no maior grau de exigência com relação à proteção florestal de nativas. Isso é justificável pela exigência do cumprimento da legislação nos dois sistemas de certificação.

\section{CONCLUSÕES}

Pelos resultados apresentados neste trabalho, pode-se concluir que:

- As áreas de manejo florestal certificadas pelo FSC superam as do PEFC no Brasil.

Tabela 6 - Comparação das áreas de proteção florestal em certificação de plantações florestais nos estados brasileiros certificados pelos sistemas FSC e CERFLOR - Dezembro de 2008.

Table 6 - Comparison of forest protected areas in forest plantation certification in Brazilian states certified by the FSC and CERFLOR systems - December, 2008.

\begin{tabular}{llrrr}
\hline \multirow{2}{*}{ Estado } & \multicolumn{2}{c}{ Área de proteção de florestas nativas em certificação de plantações florestais } \\
\cline { 3 - 5 } & & \multicolumn{2}{c}{ FSC } & CERFLOR \\
\cline { 3 - 5 } & & Área (ha) & 40,67 & Área (ha) \\
\hline 1 & Bahia & 173.104 & 34,10 & 98.123 \\
2 & Minas Gerais & 203.617 & 38,60 & 138.146 \\
3 & Paraná & 192.660 & 28,01 & 16.081 \\
4 & Rio Grande do Sul & 19.326 & 41,81 & 47.861 \\
5 & Santa Catarina & 129.610 & 21,02 & 31,72 \\
6 & São Paulo & 79.862 & & 33,103 \\
\hline
\end{tabular}

Revista Árvore, Viçosa-MG, v.35, n.4., p.859-866, 2011 
- Alguns Estados, como Pará e Amapá, possuem áreas certificadas tanto para plantações florestais quanto para florestas nativas, ao passo que outros possuem áreas certificadas para apenas uma das modalidades.

- Pelo CERFLOR, há predominância de certificação de plantações florestais em relação à certificação de florestas nativas, ao passo que há equilíbrio pelo FSC.

- As empresas com certificação de plantações florestais exercem importante função na proteção florestal, pois, em muitos casos, elas cumprem um percentual muito maior do que a exigida pela lei.

- Em média, a área destinada à proteção florestal pelo FSC é ligeiramente superior ao CERFLOR.

- Escolher um ou outro sistema de certificação não influencia no maior grau de exigência com relação à proteção de florestas nativas.

\section{REFERÊNCIAS}

ALVES, R. R. et al. Potencial de implementação da certificação florestal no Polo Moveleiro de Ubá. Revista Árvore, v.33, n.2, p.387-394, 2009a.

ALVES, R. R. et al. Certificação florestal e o mercado moveleiro nacional. Revista Árvore, v.33, n.3, p.583-589, 2009b.

AZEVEDO, T. R.; FAILLACE, S. Histórico da certificação florestal FSC. In: IMAFLORA (Org.). Brasil certificado - A história da certificação florestal no Brasil. Piracicaba: 2005. p.13-17.

BAHARUDDIN, H. J.; SIMULA, M. Certification schemes for all timber and timber products. Yokohama: ITTO - International Tropical Timber Organization, 1994. 161p.

BRTÜV. Disponível em: <http://

www.brtuv.com.br>. Acesso em 15 fev. de 2009.

BUREAU VERITAS QUALITY INTERNATIONAL BVQI - Disponível em: <http://www.bvqi.com.br>. Acesso em 11 fev. de 2009.

INMETRO. INSTITUTO NACIONAL DE METROLOGIA, NORMALIZAÇÃO E QUALIDADE INDUSTRIAL - CERFLOR. Disponível em: < http://www.inmetro.gov.br/ qualidade/cerflor.asp >. Acesso em 05 fev. 2009.
CONTROL UNION - SKAL. Disponível em: $<$ http://www.controlunion.com>. Acesso em 15 fev. de 2009.

CORRÊA, J. B. L. Quantificação das áreas de preservação permanente e reserva legal e de seus impactos econômicos na bacia do rio Pomba em Minas Gerais. 2006. 79f. Dissertação (Mestrado em Ciência Florestal) - Universidade Federal de Viçosa, Viçosa, MG, 2006.

FOREST STEWARDSHIP COUNCIL - FSC. Disponível em: <http://www.fsc.org>. Acesso em 22 fev. 2009.

GFA CONSULTING GROUP - GFA. Disponível em: $<$ http://www.gfa-group.de $>$. Acesso em $11 \mathrm{fev}$. 2009.

GIL, A. C. Métodos e técnicas de pesquisa social. São Paulo: Atlas, 2008. 200p.

INSTITUTO BRASILEIRO DE GEOGRAFIA E ESTATÍSTICA - IBGE. Disponível em: <http:// www.ibge.gov.br>. Acesso em 15 fev. de 2009.

INSTITUTO DE MANEJO E CERTIFICAÇÃO FLORESTAL E AGRÍCOLA - IMAFLORA. Manual de certificação de cadeia de custódia no sistema do Forest Stewardship Council - FSC. Piracicaba: 2002. 50p.

INSTITUTO DE ECOMERCADO - IMO. Disponível em: <http://www.imo.cl>. Acesso em 15 fev. 2009.

JACOVINE, L. A. G. et al. Processo de implementação da certificação florestal nas indústrias moveleiras nacionais. Revista Árvore, v.30, n.6, p.961-968, 2006.

JACOVINE, L. A. G. et al. Quantificação das áreas de preservação permanente e de reserva legal em propriedades da bacia do rio Pomba-MG.

Revista Árvore, v.32, n.2, p.269-278, 2008.

NARDELLI, A. M. B. Sistemas de certificação e visão de sustentabilidade no setor florestal brasileiro. 2001. $136 f$. Tese (Doutorado em Ciência Florestal) Universidade Federal de Viçosa, Viçosa, MG, 2001.

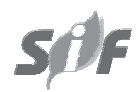

Revista Árvore, Viçosa-MG, v.35, n.4, p.859-866, 2011 
NARDELLI, A. M. B.; TOMÉ, M. V. D. F. Efeito multiplicador dos benefícios da certificação florestal. Revista Floresta, Edição Especial, p. 94-98, 2002.

NARDELLI, A. M. B.; GRIFFITH, J. J. Modelo teórico para compreensão do ambientalismo empresarial do setor florestal brasileiro. Revista Árvore, v.27, n.6, p.855-869, 2003.

NARDELLI, A. M. B. Curso de certificação florestal. Viçosa, MG: 2005. 65p. (Apostila de Curso).

PEREIRA, P.; VLOSKY, R. A history of forest certification. Louisiana: Louisiana Forest Products Development Center, 2006. 14p.

PROGRAMME FOR THE ENDORSEMENT OF FOREST CERTIFICATION - PEFC. Disponível em: $<$ http://www.pefc.org>. Acesso em 22 fev. de 2009.
SCIENTIFIC CERTIFICATION SYSTEM - SCS. Disponível em: <http://www.scscertified.com>. Acesso em 11 fev. de 2009.

SOCIÉTÉ GÉNÉRALE DE SURVEILLANCE - SGS. Disponível em: <http://www.forestry.sgs.com $>$. Acesso em 11 fev. de 2009.

SMARTWOOD. Disponível em: < http:// www.rainforest-alliance.org $>$. Acesso em $18 \mathrm{fev}$. de 2009.

INSTITUTO DE TECNOLOGIA DO PARANÁ TECPAR. -Disponível em: <http://www.tecpar.br>. Acesso em 15 fev. de 2009.

VIEHBECK, P. Cadena de custodia - manual de aplicación de procedimientos para la certificación. Santa Cruz: Consejo Boliviano para la Certificación Forestal Voluntaria, 2001. 21p. 